\title{
RELAÇÕES DE GÊNERO E ESTEREÓTIPOS FEMININOS EM ANÚNCIOS DE ONTEM E DE HOJE
}

\author{
FRANK ANTONIO MEZZOMO \\ Universidade Estadual do Paraná (UNESPAR) \\ IVANIA SKURA \\ Universidade Estadual do Paraná (UNESPAR) \\ CRIStina Satiê De Oliveira PÁtaro \\ Universidade Estadual do Paraná (UNESPAR)
}

\section{RESUMO}

Esta investigação tece reflexões questionando estereótipos femininos que evidenciam desvalorizações da mulher na mídia, e busca demonstrar que ferramentas como a propaganda não só permitem difundir discursos sexistas, mas também possibilitam abordar criticamente as relações de gênero. Para ilustrar esta discussão, foram elencados anúncios publicitários com relações intertextuais que apresentam representações de caráter generalizante e outros que combatem visões sexistas, de diferentes temporalidades e contextos. Os anúncios que ilustram o estudo têm a mulher como figura central e apelos que reiteram ou desconstroem desigualdades de gênero, denotando mudanças e permanências nas representações de ontem e de hoje. A partir dos materiais analisados, argumenta-se que os estereótipos presentes nas comunicações têm servido de modelo e parâmetro para dissolver diferentes modelos femininos, e também revelam as marcações de relações entre mulheres e homens, apontando para desafios tais como a problematização das estruturas sociais discriminatórias.

\section{ABSTRACT}

This research weaves reflections that questions female stereotypes that show woman devaluations in the media and seeks to demonstrate that tools such as advertising not only allow to spread sexist speeches but also allows to critically approach gender relations. To illustrate this argument, there were brought in commercials with intertextual relations that addressed generalizing representations and others that fight sexist views, from different times and contexts. The ads that illustrated the study have the woman as the central figure and have appeals that reiterate or deconstruct gender inequality, denoting changes and continuities in yesterday's and today's representations. From the materials analyzed, it is argued that stereotypes present at the communications have served as a model and parameter to dissolve different female models, and also reveal the markings of relations between women and men, pointing to challenges such as the problematization of discriminatory social structures.

KEYWORDS: Gender; Women; Advertising.

PALAVRAS-CHAVE: Gênero; Mulher; Propaganda. 


\section{Introdução}

Este texto tem o objetivo de refletir sobre o papel da propagando na construção e na desconstrução de estereótipos femininos. Assim, discute-se, por exemplo, como a estreita associação da mulher com a esfera doméstica, usualmente tratada como natural ou inevitável, é, na verdade, uma construção social e, nesta direção, questionam-se estereótipos midiáticos que usualmente colocam figuras femininas em um papel de cuidadoras do lar, dos filhos e também de si mesmas, atendendo às exigências de padrões de beleza e comportamento provenientes de discursos e de modelos sociais normatizadores.

Para articular discussões teóricas e empiria, elencamos anúncios cujos argumentos centrais evidenciaram entre si uma intertextualidade temática, abordando estereótipos femininos em diferentes temporalidades e formatos, baseando-se em consensos e noções vigentes que se repetem anonimamente através do tempo ${ }^{1}$. A intertextualidade, nesta direção, como perspectiva interdiscursiva e interdisciplinar, investe no amplo relacionamento entre textos e cultura, redefinindo práticas de leitura ${ }^{2}$, buscando significados que estão além do visível e tratando do diálogo entre textos e produções de sentidos.

Olhamos para essas fontes avaliando que "as representações sociais veiculadas nos anúncios publicitários desempenham uma parte importante, se não a mais importante, na relação entre a publicidade e sociedade ${ }^{\prime \prime 3}$ e, dessa maneira, pela lente conceitual dos estudos de gênero, apontaremos alguns caminhos para reflexão e debate.

A noção de gênero aqui empregada "refere-se à institucionalização social das diferenças sexuais; é um conceito usado por aqueles que entendem não apenas a desigualdade sexual, mas muitas das diferenciações sexuais, como socialmente construídas ${ }^{\prime \prime}$. Esta noção é produto de variadas forças sociais e tem cunho interdisciplinar, pois abarca aspectos culturais, históricos e socioeconômicos da perpetuação do gênero, visto, neste momento, como uma categorização mutável e complexa.

Por isso, "gênero" é um termo usado por aqueles que defenderam que a área acadêmica de estudos sobre mulheres iria transformar os paradigmas disciplinares e as problematizações das representações femininas do passado, permitindo discutir também as práticas atuais ${ }^{5}$, de modo que, abandonando determinismos biológicos e falsas noções de modelos fixos para homens e mulheres, seria possível se desfazer de uma visão generalizante. É válido questionar modelos limitadores, principalmente porque, na concretude destes, é

\footnotetext{
${ }^{1} \mathrm{KOCH}$, Ingedore Villaça. Intertextualidade: diálogos possíveis. São Paulo: Cortez, 2007.

${ }^{2}$ CARVALHAL, Tania Franco. O próprio e o alheio: ensaios de literatura comparada. Rio Grande do Sul: Editora da Universidade do Vale do Rio dos Sinos, 2003.

${ }^{3}$ GASTALDO, Édison. Publicidade e sociedade: uma perspectiva antropológica. Porto Alegre: Sulina, 2013, p. 20.

${ }^{4}$ OKIN, Susan. O gênero, o público e o privado. Estudos Feministas, Florianópolis, v. 16, n. 2, p. 305-332, 2008, p. 306.

5 SCOTT, Joan W. Gender: A useful category of historical analysis. The American Historical Review, v. 91, n. 5, p. 1053-1075, 1986.
} 
possível verificar que os mesmos foram reiterados por gerações através de diversas mídias, discursos e demais normatizações, que, ao fim e ao cabo, vão moldando perfis e construindo no imaginário social conceitos e concepções do que é ou não "adequado", certo ou errado, bom ou mau.

Se, no espaço da significação, as representações colocam-se como formas de classificar e de perceber - isto é, como instituições sociais que denotam divisões da organização social e práticas que constroem o próprio mundo social ${ }^{6}$-, as representações de mulheres são modos de produzir significados na cultura, pela linguagem, e a produção de sentidos se dá por sistemas simbólicos que são atravessados por instituições, instrumentos, saberes e poderes". Como expressa Chartier, as representações "não são simples imagens, verídicas ou enganosas, do mundo social. Elas têm uma energia própria que persuade seus leitores ou seus espectadores" ${ }^{\prime 8}$.

É preciso olhar para essas representações, portanto, como construções que dialetizam o real e que, ao mesmo tempo constroem e desconstroem práticas e significados. A colocação de que nenhum destino biológico define a forma que a mulher assume na sociedade, reiterada pela célebre frase "ninguém nasce mulher, torna-se mulher", de Simone de Beauvoir ${ }^{9}$, corrobora, portanto, para explicitar o questionamento da mediação midiática que impõe padrões de comportamento e "rotulações" femininas que são ensinadas e sofrem vigilância.

Esses modelos constantemente reiterados acabam por ser fortalecidas e estabelecem, por exemplo, uma diversidade de obrigações femininas como as de manter-se bela, de cuidar da casa, marido e filhos, conforme observaremos nos exemplos trazidos a seguir. Não é cabível, no entanto, aqui apontar representações como falsas ou verdadeiras, mas percebê-las dentro de um contexto histórico específico, como práticas constituintes de uma realidade social que generaliza posições e interpretações capazes de estabelecer ou sustentar relações de poder.

A análise pode apontar categorias e classificações, percebidas através da linguagem e da representação, quanto ao modo como o conhecimento é institucionalizado, modelando práticas sociais e pondo novas práticas em funcionamento ${ }^{10}$. E no intuito de evidenciar discriminações e desvalorizações, são apresentados, neste texto, anúncios publicitários ${ }^{11}$ que retomam estas

\footnotetext{
${ }^{6}$ CHARTIER, Roger. O mundo como representação. Revista Estudos Avançados, São Paulo, v. 5, n. 11, p. 173-191, 1991. Disponível em: <http://www.usp.br/cje/anexos/pierre/CHARTIERROmundocomorepresentacao.pdf>. Acesso em: 20 fev. 2015.

${ }^{7}$ SANTAELLA, Lucia. Corpo e comunicação. São Paulo: Paulus, 2004.

${ }^{8}$ CHARTIER, Roger. Uma trajetória intelectual: livros, leituras, literaturas. In: ROCHA, João Cezar de Castro (org.). Roger Chartier - $A$ força das representações. história e ficção. Chapecó: Argos, 2011, p. 21-54.

${ }^{9}$ BEAUVOIR, Simone. O segundo sexo. Rio de Janeiro: Nova Fronteira, 1980, p. 9.

${ }^{10}$ HALL, Stuart. A centralidade da cultura: notas sobre as revoluções culturais do nosso tempo. Educação e Realidade, v. 22, n. 2, jul./dez., p. 15-46, 1997.

${ }^{11}$ Neste texto, as palavras anúncio, publicidade e propaganda são usadas como nomenclaturas
} 
categorizações, discutindo relações de gênero e estereótipos femininos ali presentes $^{12}$.

O corpus do estudo, deste modo, contou com três propagandas de 1967, publicadas em uma mídia impressa norte-paranaense de grande abrangência regional; outras duas de 2014 e 2015, publicadas no ambiente digital por uma marca nacional de renome; e dois anúncios atuais (2014) também veiculados online, assinados por organizações que reconhecem e questionam papéis de gênero e que visaram combater práticas sexistas.

Compreende-se que as mídias são produtos culturais e, ao mesmo tempo, portadoras de concepções e visões de mundo que merecem um olhar crítico $^{13}$. A imprensa, como fonte e objeto de pesquisa, permite compreender a trajetória humana, o passado e suas complexidades. Essa abordagem, dessa maneira, é feita com base em um olhar não positivista, inaugurado pela escola dos Annales ${ }^{14}$, que ganha notoriedade, sobretudo, a partir da década de 1970, por intermédio da ampliação de problemas, objetos e abordagens de estudos dando corpo a uma nova perspectiva historiográfica ${ }^{15}$.

A relação entre História e fontes de pesquisa foi redimensionada a partir do momento em que a confluência desta com outras ciências possibilitou olhar para novos materiais com possibilidades de serem problematizados. As fontes passaram a ser aquilo que o historiador enxerga como passível de análise, compreensão e interpretação ${ }^{16}$. A importância da nova abordagem foi decisiva não apenas para a História, mas também para campos de saberes vizinhos,

sinônimas. Usualmente, classifica-se propaganda como a propagação de conceitos e ideias num sentido mais abstrato - e publicidade como a comunicação de produtos e serviços, num sentido mais concreto. Cf. LUPETTI, Marcélia. Gestão estratégica da comunicação mercadológica. São Paulo: Thomson Learning, 2007.

12 Ao abordar os anúncios publicitários e a transmissão de informação midiática, compreendemos que esta não pode ser enxergada de modo linear, num modelo de comportamento que crie a ilusão de uma absorção automática da informação. Pelo contrário, trata-se de um processo bastante complexo, que implica uma relação que envolve elementos diversos como cultura, sujeitos, códigos, e não possui fim nem começo determinados. Cf. MARTINO, Luiz C; HOHLFELDT, Antonio. FRANÇA, Vera Veiga (org.). Teorias da comunicação: Conceitos, escolas e tendências. Petrópolis: Vozes, 2001.

${ }^{13}$ ADORNO, Theodor. Indústria cultural e sociedade. São Paulo: Paz e Terra, 2009.

${ }^{14}$ Os Annales d'Histoire Économique et Sociale foi uma revista acadêmica francesa que, na intenção de problematizar as perspectivas hegemônicas da época, difundiu uma abordagem nova e interdisciplinar da história, voltada para o método das ciências sociais. No movimento dos Annales expressaram-se inquietudes e experiências de um novo exercício histórico, ao propor a pesquisa de sujeitos e objetos como mulher e família, infância e educação, livro e leitura etc., tratando do cotidiano e das contradições da história humana num movimento desenraizado da noção positivista, Cf. RIBEIRO, Betânia de Oliveira Laterza; SILVA, Elizabeth Farias da; SILVA, Maria Aparecida Alves. Jornal como fonte: uma das pontas do iceberg nas narrativas em história da educação. Cadernos de História da Educação, Uberlândia, v. 13, n. 1, jan./jun., 2014.

${ }^{15}$ LE GOFF, Jacques; NORA, Pierre. (orgs.). História: Novos Problemas, Novas Abordagens, Novos Objetos. Rio de Janeiro: Francisco Alves, 1988.

16 SILVA, Márcia Pereira; FRANCO, Gilmara Yoshihara. Imprensa e política no Brasil: considerações sobre o uso do jornal como fonte de pesquisa histórica. Revista História em Reflexão, Dourados, v. 4, n. 8, p. 1-11, jul./dez. 2010. 
promovendo diálogos interdisciplinares e vinculações da pesquisa histórica às preocupações e problemas da contemporaneidade ${ }^{17}$.

A escolha por investigar como se constituiu a representação da mulher em fontes de diferentes temporalidades vem, portanto, justamente da visão de que a pesquisa histórica com fontes da imprensa possibilita o conhecimento de articulações conceituais e reverberações que, possivelmente, são observadas no presente e podem se projetar no devir.

\section{A bela "rainha do lar": uma representação que perpassa gerações}

Nos ditos Anos Dourados do Brasil (1945-1964) notavam-se as distinções de gênero de modo bastante evidente ${ }^{18}$ ao passo que em diversos meios propagava-se a imagem da mulher como a mãe e dona de casa dedicada ao lar e aos filhos, e do homem como marido ou pai provedor, fortalecendo-se a noção de que "as mulheres têm sido vistas como 'naturalmente' inadequadas à esfera pública, dependentes dos homens e subordinadas à família"19. As esposas e mães dos Anos Dourados eram valorizadas por sua capacidade de tomar responsabilidades ligadas à felicidade doméstica, agradando aos filhos e ao marido ${ }^{20}$.

Tratando especialmente de discursos dos anos 1960, e buscando evidenciar mudanças e permanências em relação a anúncios atuais dirigidos ao público feminino, esses papéis demarcados são aqui ilustrados para trazer exemplos à discussão de gênero como um marcador de diferença que, muitas vezes, pode encontrar resistência por parte de homens e mulheres por lidar com uma desconstrução do que está posto. As análises trazidas neste momento, giram em torno da concepção de que "o problema com o gênero é que ele prescreve como devemos ser em vez de reconhecer como somos" ${ }^{\prime \prime 2}$.

Para a discussão sobre gênero e estereótipos femininos em anúncios, ilustrando a já exposta imagem comum que retrata a mulher dos anos 1960 como "rainha do lar", selecionamos três anúncios publicitários publicados na mídia impressa norte-paranaense em 1967 (Imagens 1, 2 e 3). 0 jornal em que se materializaram as propagandas a seguir, denominado Folha do Norte do Paraná, foi criado em 1962 e publicou seu último exemplar em 1979. Embora fosse de posse da Igreja Católica, diocese de Maringá-PR, o periódico tinha

17 BARBOSA, Marialva Carlos. Escola dos anais. In: CITELLI, Adilson; BERGER, Christa; BACCEGA, Maria Aparecida; LOPES, Maria Immacolata Vassallo de; FRANÇA, Vera Veiga (orgs.). Dicionário de comunicação: escolas, teorias e autores. São Paulo: Contexto, 2014, p. 192-200.

${ }^{18}$ PINSKY, Carla Bassanezi. Mulheres dos anos dourados. São Paulo: Contexto, 2014.

${ }^{19}$ OKIN, op. Cit., 2008, p. 308.

${ }^{20}$ DEL PRIORE, Mary. Histórias íntimas: sexualidade e erotismo na história do Brasil. 2 ed., São Paulo: 2014.

${ }^{21}$ ADICHIE, Chimamanda Ngozi. We should all be feminists. Produção: TEDx Euston. 30'15". TED Talks, 2013. 1080p (HD). Disponível em: <http://youtu.be/hg3umXU_qWc>. Acesso em 20 fev. 2014. 
cunho comercial e, por isso, continha propagandas de grandes marcas locais e nacionais que assinavam os anúncios. O jornal foi considerado uma das principais mídias impressas dos anos 1960 e 1970 na região norte paranaense e chegou a circular em 200 municípios do estado, além de distribuição de vendas em São Paulo e Santa Catarina.

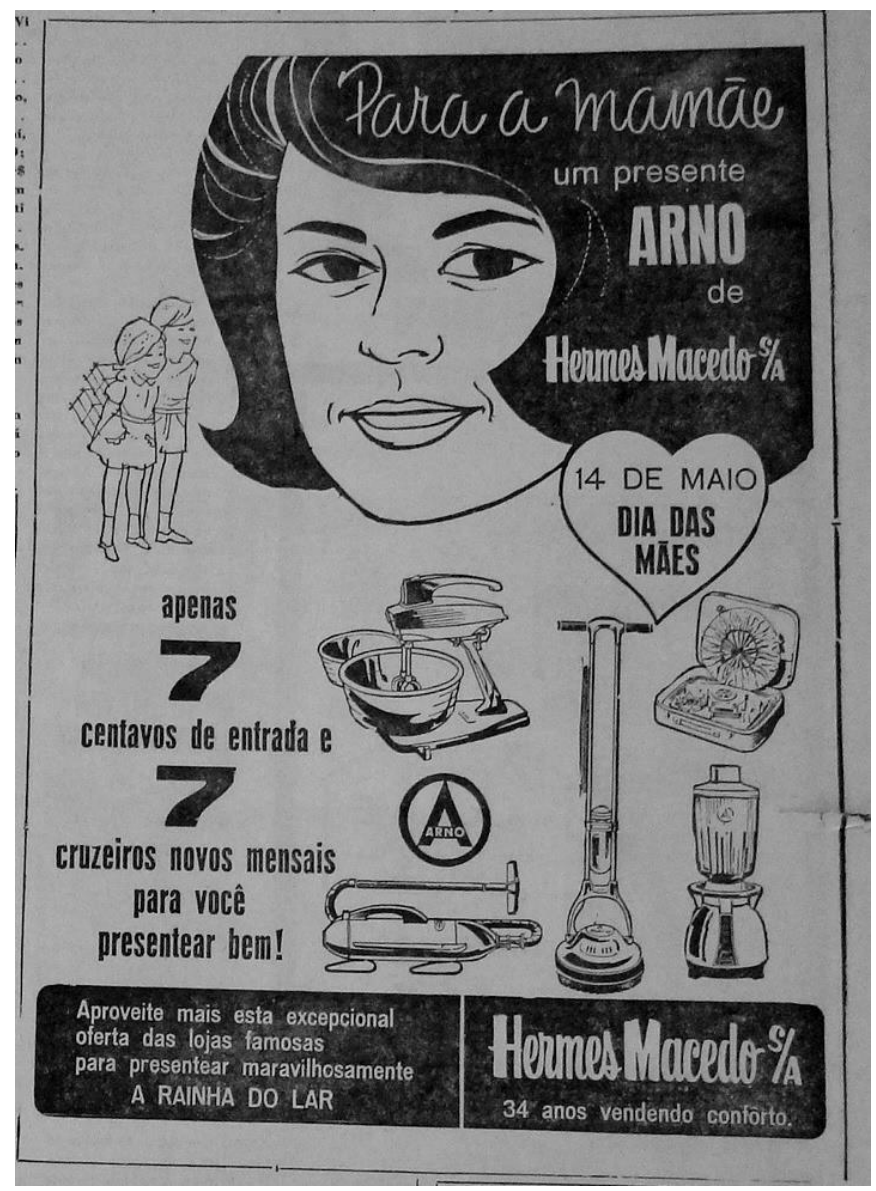

Imagem 1 - Anúncio Arno 1967.

Fonte: Jornal Folha do Norte do Paraná (23 abr. 1967).

Na propaganda da Imagem 1, o significado do título "Para a mamãe um presente Arno de Hermes Macedo S/A" é ancorado pelo box de apoio em formato de coração que anuncia "14 de maio, dia das mães", explicitando o motivo da promoção e o apelo de venda. Com uma imagem de uma mulher ao fundo e de duas crianças ao lado segurando o que se assemelha a caixas de presentes atrás de si, como que para surpreender a mãe presenteando-a, a propaganda explica: "apenas 7 centavos de entrada e 7 cruzeiros novos mensais para você presentear bem!". Ao lado, há desenhos de produtos como batedeira, aspirador de pó, enceradeira, liquidificador, em volta do logotipo da marca. Num último box, em contraste, a peça assina: "Aproveite mais esta excepcional oferta das lojas famosas para presentear maravilhosamente $A$ RAINHA DO LAR. Hermes Macedo S/A. 34 anos vendendo conforto". 
Ali fica latente a noção de que a mulher-mãe tem para si os eletrodomésticos como boas e apropriadas opções de presentes, já que estes fazem parte de sua vivência diária22.

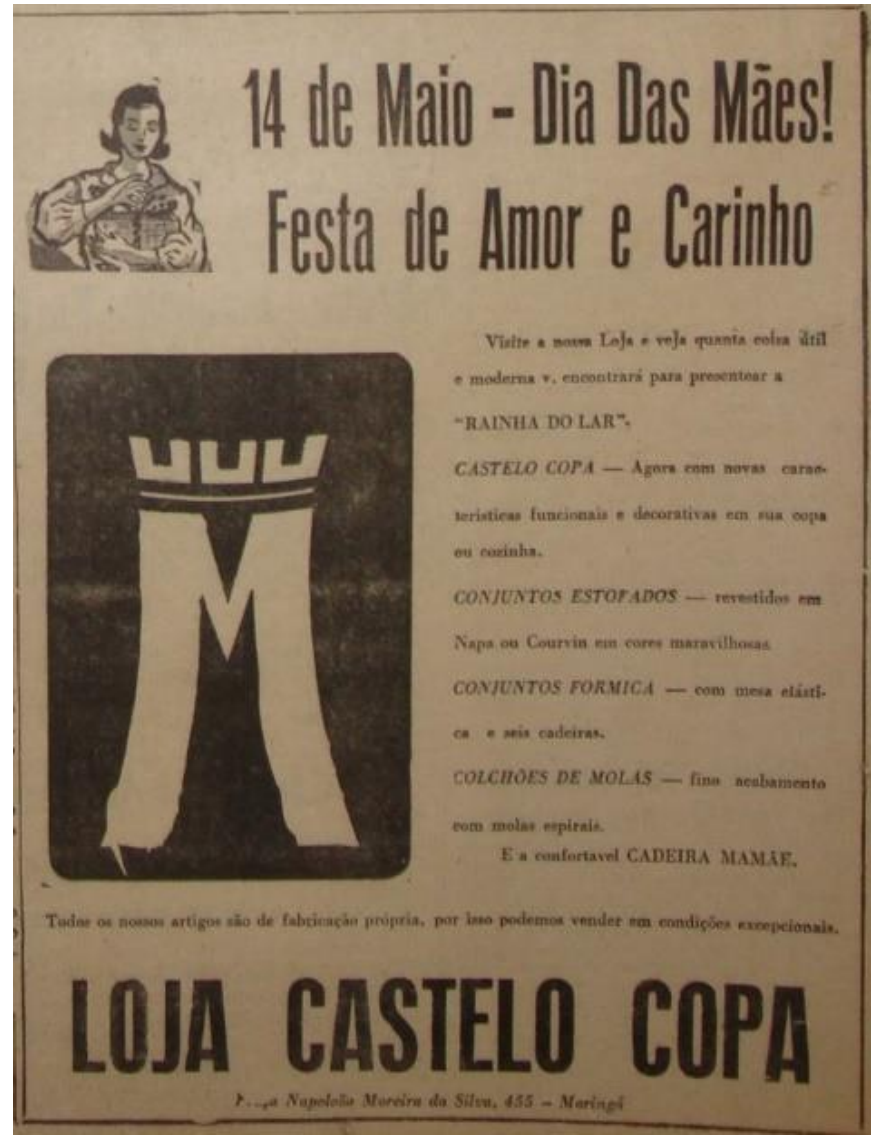

Imagem 2 - Anúncio Castelo Copa 1967.

Fonte: Jornal Folha do Norte do Paraná (6 mai. 1967).

Com a mesma linha criativa, o apelo publicitário da Loja Castelo Copa (Imagem 2) ilustra o anúncio com uma figura feminina e usa o título: "14 de Maio - Dia das Mães! Festa de Amor e Carinho". Ao lado de uma grande imagem do logotipo, segue o texto explicativo: "Visite a nossa loja e veja quanta coisa útil e moderna v. encontrará para presentear a 'RAINHA DO LAR'". Reitera-se o apelo de venda com a frase "Castelo Copa - Agora com novas características funcionais e decorativas em sua copa ou cozinha" e são listados alguns produtos, tais como conjuntos estofados e fórmica, colchões de molas e

\footnotetext{
22 Destaca-se que, no contexto tratado, quando se fala de "mulher", as mensagens dirigiam-se geralmente às mulheres brancas, com determinada capacidade de consumo e estilo de vida. Discussões sobre marcadores sociais de diferenças que envolvem raça/etnia e classe social/segmento econômico, embora não sejam foco desta discussão e não sejam aqui contempladas, podem enriquecer a problematização do tema em questão. As representações presentes nos anúncios analisados, ainda, não são compreendidas como espelhos da realidade social de sua época, mas como materializações de discursos em meios privilegiados evidenciando valores, culturas e modelos sociais que interferiram e interferem na construção de uma cultura de (des)igualdade de gênero.
} 
a "confortável cadeira mamãe" (não há ilustração ou descrição da cadeira ofertada). O anúncio termina alertando: "Todos os nossos artigos são de fabricação própria, por isso podemos vender com condições excepcionais", seguidos da assinatura da marca e o endereço do ponto de venda.

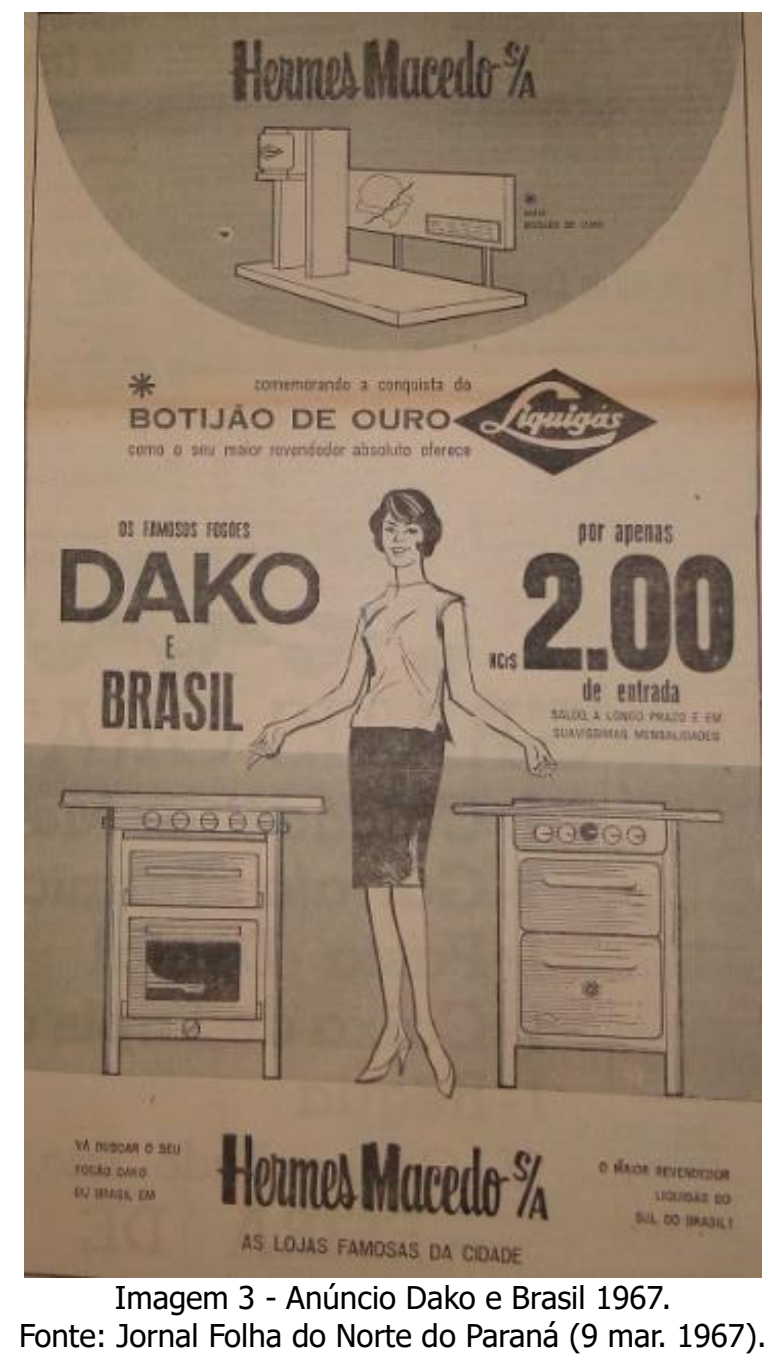

Já na Imagem 3, a peça publicitária da loja Hermes Macedo S/A, anunciando produtos das marcas Dako e Brasil, também abordou a figura da "rainha do lar", ainda que não tenha utilizado o termo no apelo de vendas (como se notou nas imagens 1 e 2, por exemplo). A figura feminina central no anúncio está posicionada entre dois fogões, exibindo contentamento e satisfação ao apontar para os produtos. O texto inicial introduz: "Hermes Macedo S/A - Comemorando a conquista do botijão de ouro Liquigás como o seu maior revendedor absoluto oferece - os famosos fogões DAKO e BRASIL", de modo que seguem as informações de venda "Por apenas Cr\$ 2.00 de entrada. Saldo a longo prazo e em suavíssimas mensalidades". Repete-se o apelo assinando a propaganda "Vá buscar o seu fogão Dako ou Brasil em Hermes e Macedo S/A, as lojas famosas da cidade - o maior revendedor Liquigás do sul do país!". 
Ao mesmo tempo em que se promove a marca das lojas e busca-se atrair o público para o ponto de venda, nessas peças é retomada a noção vigente à época de que, quando se trata de vender produtos de cozinha, eletrodomésticos e mercadorias para o lar (seja em datas comemorativas como o dia das mães ou em outro momento festivo), a mulher é o público adequado para se abordar ou para se presentear, pois a ela cabem essas atribuições.

Estas representações estão intrinsecamente ligadas a diferenças de gênero, de modo que:

é bastante razoável pensar que, por exemplo, em troca da inferioridade do feminino na hierarquia de gênero, o discurso da ordem e da estabilidade atribua à dona de casa o título de "rainha do lar" a fim de promover o conformismo e a manutenção das relações estabelecidas. [...] A ideia de que a mulher é efetivamente a "rainha do lar" pode contribuir para mantê-la como tal sem alternativas ${ }^{23}$.

Este título de "rainha do lar", empregado nas imagens 1 e 2, é um termo recorrente e, portanto, bastante comum nas comunicações dos anos 1960. Na atualidade, o mesmo apelido dado às donas de casa já é menos usual em mensagens comerciais, mas parece manter-se incorporado aos conceitos publicitários. Exemplo disso é o recente anúncio publicado na página oficial da marca de eletrodomésticos Arno, na rede social digital Facebook, que retoma a ideia de mulher que merece presentes como eletrodomésticos na data comercial que comemora o dia das mães (Imagem 4).

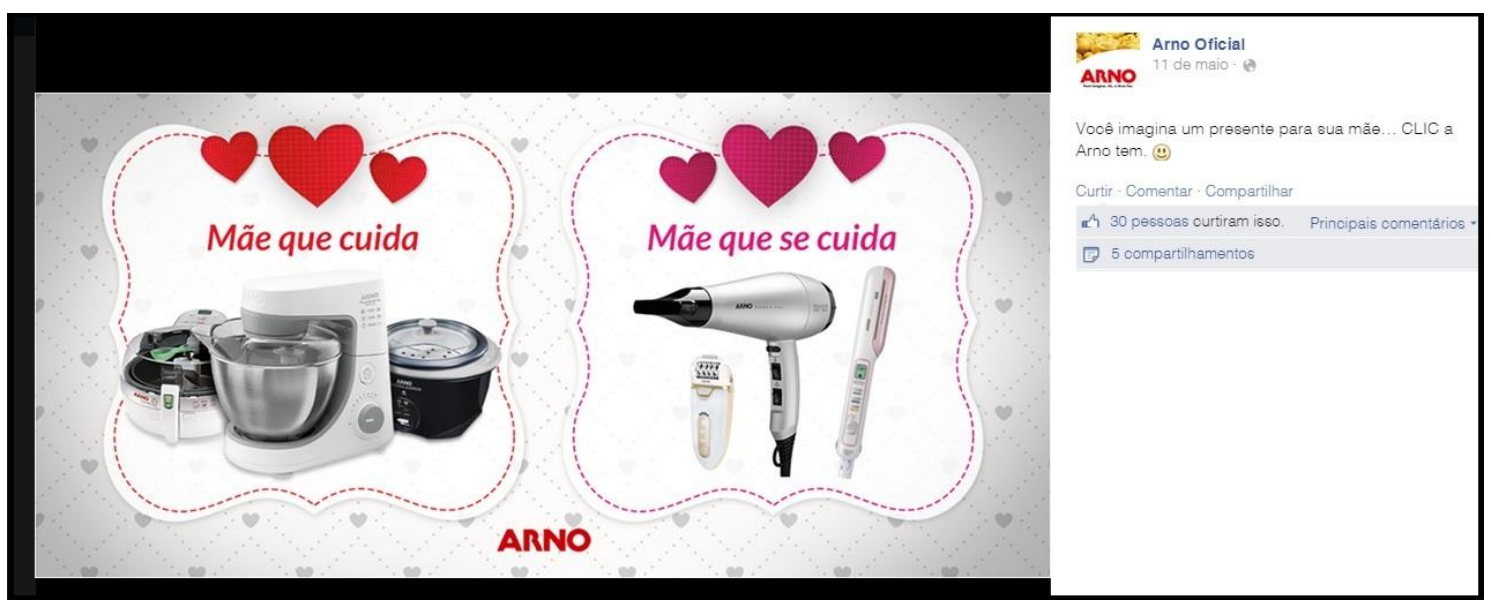

Imagem 4 - Anúncio Arno 2014.

Fonte: Facebook Arno Oficial (11 mai. 2014) ${ }^{24}$

A fanpage legenda a imagem com a afirmação "Você imagina um presente para sua mãe... CLIC a Arno tem" seguido de um emoticon smiley ${ }^{25}$

\footnotetext{
${ }^{23}$ PINSKY, op. cit., 2014, p. 284-285.

${ }^{24}$ Postagem disponível em: <http://goo.gl/vMpFWe>. Acesso em: 20 fev. 2015.
} 
numa substituição de palavras que remete ao slogan oficial da marca em suas últimas campanhas "Você imagina, clic, a Arno faz". A publicação assinada pela Arno, veiculada em 11 de maio de 2014, lembra que a data de comemoração do dia das mães se aproxima e sugere a compra dos produtos da marca para presentear as mães, retomando um lugar-comum que não só se faz presente em discursos comerciais, como também no mundo social, onde às mães cabe o espaço doméstico e, tendo o controle desta esfera, a elas seriam úteis os eletrodomésticos, já que estes aparelhos as auxiliam e facilitam sua tarefa de cuidar do lar e dos filhos.

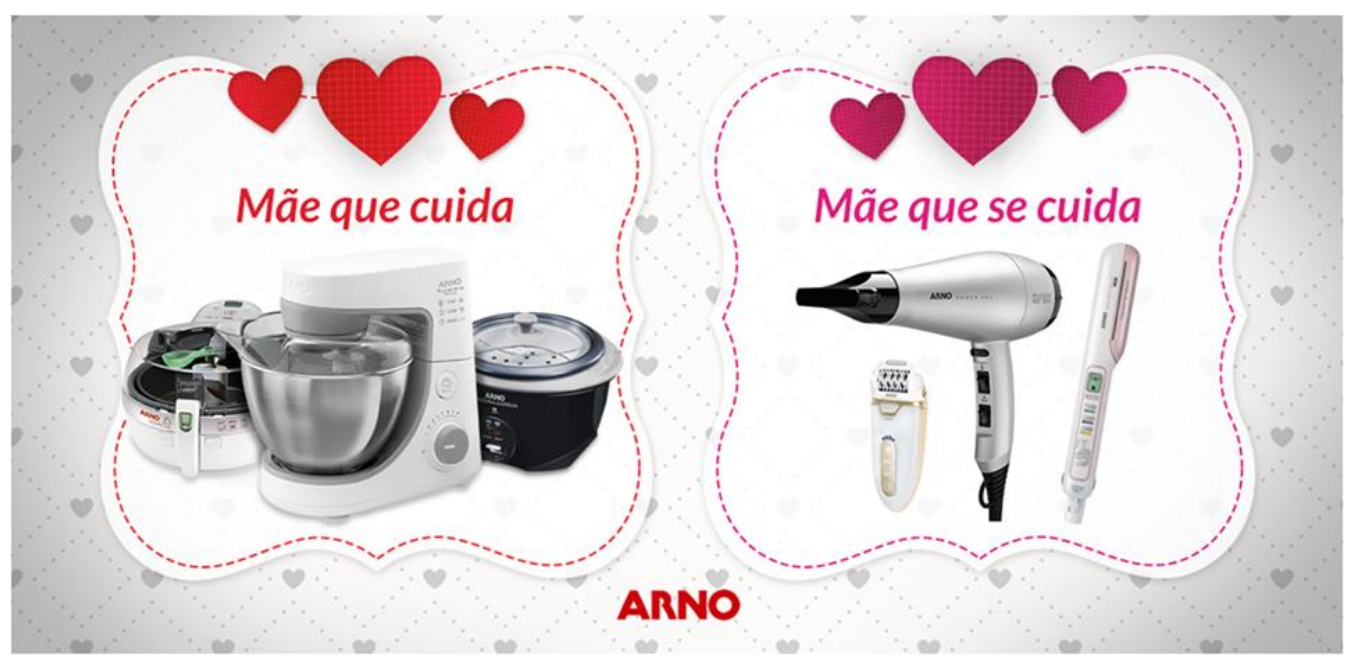

Imagem 5 - Anúncio Arno 2014 ampliado. Fonte: Facebook Arno Oficial (11 mai. 2014) ${ }^{26}$.

Na propaganda ampliada (imagem 5), analisam-se as fotos ilustrativas de uma fritadeira e uma panela elétrica, com uma batedeira à frente, em que o sentido se ancora pelo título "Mãe que cuida", numa significação em que a tradicional imagem da mãe que cozinha para a família assim expressa seu amor (o próprio plano de fundo e imagem dos produtos têm moldura que utiliza símbolos de corações, geralmente ligados a significações de carinho). A segunda parte do anúncio "Mãe que se cuida", num jogo de palavras que retoma a primeira colocação, denota que a mulher deve cuidar dos outros, mas também de si, já que as imagens logo abaixo são de itens geralmente ligados à beleza feminina: um depilador, um secador de cabelos e uma chapinha de alisamento/babyliss, que se segue pela assinatura da marca centralizada em destaque ao fim da propaganda.

Em 5 de maio de 2015, novamente em celebração do dia das mães, sob o mote "\#minhamãemerece"27, a marca retoma o sentido da campanha

\footnotetext{
${ }^{25}$ Emoticon, que une a palavra emotion (emoção) com icon (ícone) é uma forma de expressarse em mensagens curtas, que tornou-se bastante popular principalmente no ambiente digital. 0 smiley é um dos mais clássicos emoticons: um círculo geralmente preenchido de amarelo que aparenta sorrir - (-) - expresso pelos caracteres ":" e ")".

${ }^{26}$ Postagem disponível em: <http://goo.gl/vMpFWe>. Acesso em: 20 fev. 2015.
} 
passada. A imagem de uma mãe com sua filha na cozinha é pano de fundo para o lançamento de um novo eletrodoméstico: "A Planetária Dual, assim como as mães, é multifuncional. 2 em 1, podendo ser liquidificador ou batedeira. Contém 3 tipos de batedores, um para cada tipo de massa. Ela é a porta de entrada para conhecer novas receitas! \#MinhaMãeMerece", é a legenda do anúncio.

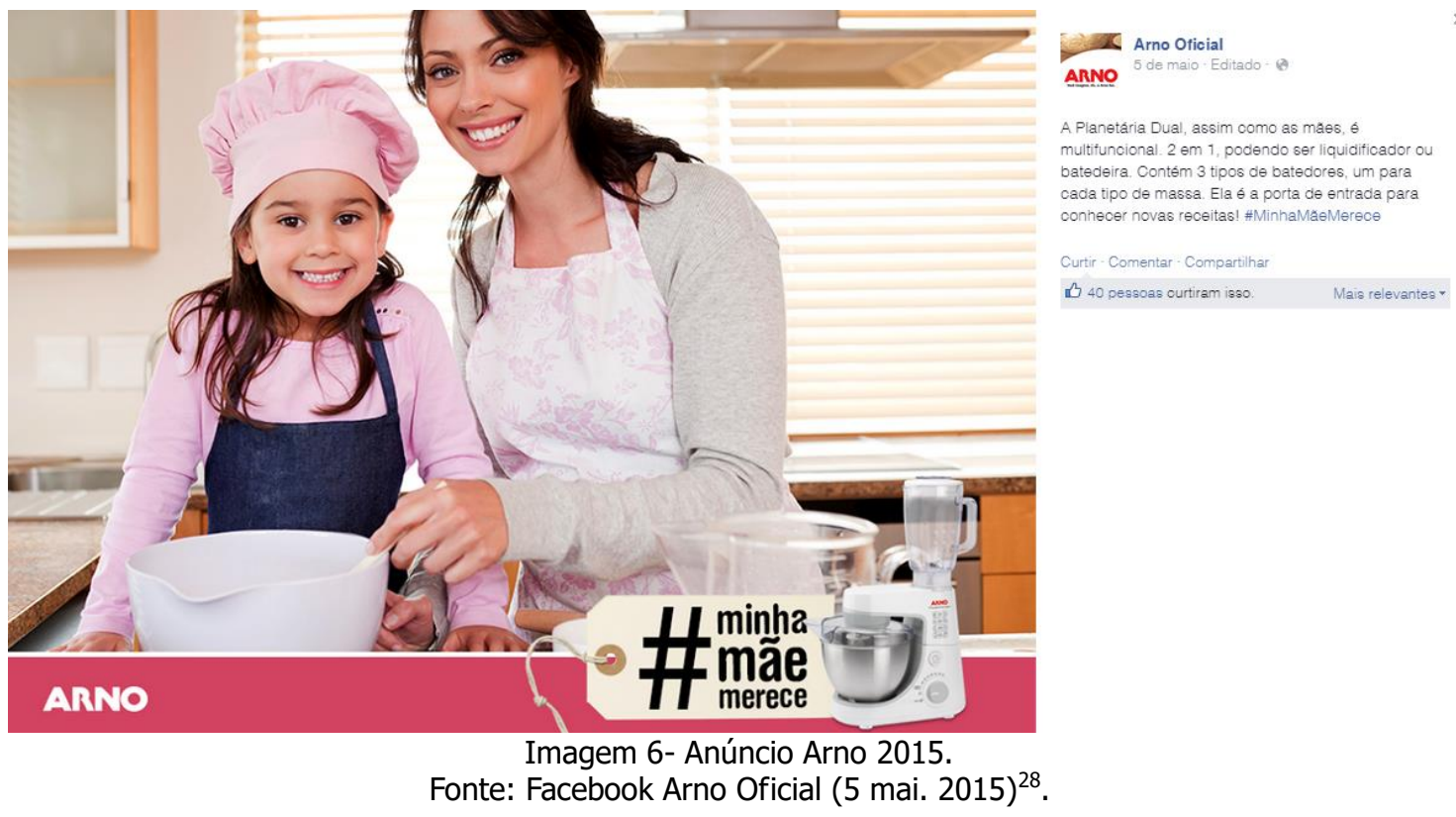

Sobre os estereótipos apresentados nos anúncios (da mulher invariavelmente valorizada por cuidar da casa/filhos e manter-se bela), questiona-se o caráter generalizante que possuem, que dissolve diferenças e perpetua argumentos explícitos sobre a família, relacionados à "natureza" da mulher: do cuidado, do senso de maternidade, do talento para atividades domésticas, etc.

É nesta direção que "pesquisadoras feministas têm argumentado que a divisão doméstica do trabalho, e especialmente a prevalência da mulher à frente da criação dos filhos, são socialmente construídas" ${ }^{\prime 29}$, porque esses discursos vêm sendo repetidos, em diversos contextos, com o passar do tempo e, deste modo, tendem a se consolidar, legitimar papéis e funções sociais.

A associação imediata da mulher com a esfera doméstica, seja numa propaganda ou num pensamento automatizado da convivência diária, reafirma desigualdades. Esses vínculos não são naturais e, portanto, não podem ser vistos desta maneira, principalmente porque "a desigualdade social entre 0

${ }^{27}$ O uso do caractere "\#", recurso denominado hashtag, é utilizado como marcador de palavraschave no ambiente digital. Nas redes sociais digitais, tem a função de categorizar conteúdos similares facilitando a busca e a integração entre usuários.

${ }_{28}$ Postagem disponível em: <https://goo.gl/1V570l>. Acesso em: 19 jun. 2015.

${ }^{29}$ OKIN, op. cit., 2008, p. 315. 
masculino e o feminino é uma construção social, cultural" ${ }^{\prime 30}$. Do mesmo modo, 0 discurso frequente da beleza como sinônimo de feminilidade, se analisado de perto, pode ser melhor compreendido e problematizado.

O corpo, assim como as maneiras de se comportar estão ligadas a uma economia doméstica e social, uma subjetividade dominante ${ }^{31}$. Essas representações contemporâneas parecem perpetuar-se já que, conforme lembra Almeida, já no início do século XX, "as virtudes próprias da feminilidade pautavam-se no recato, na docilidade, na afetividade mais desenvolvida, na receptividade passiva em relação aos desejos e necessidades dos homens e, mais tarde, dos filhos"132. Do mesmo modo, Alves afirma: "das mulheres esperase que sejam: simpáticas, atenciosas, submissas, sorridentes e discretas" ${ }^{\prime \prime 3}$. Continua o autor em outro livro:

tem-se claramente a intenção de inserir a mulher no âmbito da dependência simbólica em que ela primeiro existe pelo e para o olhar dos outros. Decorre desse entendimento a expectativa que ela seja receptiva, atraente e esteja sempre disponível para agradar ao homem. Por isso, dela é esperado simpatia, atenção e submissão ${ }^{34}$.

Certamente as noções de feminilidade, assim como a de beleza, por exemplo, variam conforme o contexto histórico, além de ser um conceito em constante recomposição. De maneira geral, e em especial na publicidade, a posição social da mulher é colocada de maneira que as representações não contemplem diversidades de modo de ser, pelo contrário, o cuidado com a beleza é imperativo e, inclusive, "ideias como sacrifício, dedicação e necessidade, estão associadas à função da mulher" ${ }^{\prime \prime 3}$. Nas imagens publicitárias, os apelos demonstram que as "mulheres livres" não são aquelas que podem fazer escolhas, mas as que se conformam aos modelos da mídia, que só se enxergam pelo olhar do homem, reforçando a ideia de superioridade do masculino ${ }^{36}$.

\footnotetext{
${ }^{30}$ ALMEIDA, Anailde. A construção social do ser homem e ser mulher. Salvador: EDUNEB, 2010, p. 13.

31 SIQUEIRA, Denise da Costa Oliveira; FARIA, Aline Almeida de. Corpo, saúde e beleza: representações sociais nas revistas femininas. Revista Comunicação, Mídia e Consumo. São Paulo, v.3, n. 9, p. 171-188, 2007.

32 ALMEIDA, Angela Maria Menezes de. Feminilidade: caminho de subjetivação. Estudos de Psicanálise, Belo Horizonte, v. 4, n. 38, p. 29-44, 2012, p. 30.

33 ALVES, Fábio Lopes. Pós-mulher: corpo, gênero e sedução. Curitiba: Editora Champagnat, 2014.

${ }^{34}$ ALVES, Fábio Lopes. Noites de cabaré: prostituição feminina, gênero e sociabilidade na zona de meretrício. 2. ed. São Paulo: Arte e Ciência, 2012.

35 FARIA; Lia Ciomar Macedo de; CUNHA, Washington Dener dos Santos; SILVA, Rosemaria Josefa Vieira da. Memórias e representações femininas: Ideologias e Utopias dos anos 60. Revista Vozes dos Vales da UFVJM, Minas Gerais, v. 1, n. 2, p. 1-14, 2012, p. 11.

${ }^{36}$ DEL PRIORE, Mary. Histórias e conversas de mulher: amor, sexo, casamento e trabalho em mais de 200 anos de história. São Paulo: Planeta, 2014.
} 
De certa forma, coloca-se que a manutenção da beleza, entre outros atributos, imperava, nos anos 1960 e 1970, como uma condição para o sucesso do casamento, responsabilidade delegada à mulher ${ }^{37}$. Nesse movimento, "cristalizam-se no corpo as crenças, as representações e os significados do que é ser homem ou mulher em determinada sociedade, em determinado momento" ${ }^{\prime 38}$ e esses modelos vão se fortalecendo se não forem relativizados e discutidos.

Se tradicionalmente "a chamada boa aparência impunha-se. Os bons casamentos sobretudo dependiam dela" ${ }^{\prime 39}$, significa que a beleza, além de ser uma forma de igualar as relações de poder, ligadas à sedução e a valores que supervalorizam a boa aparência, passa a ser definidora de mulher e função a ser cumprida socialmente ${ }^{40}$. Tratam-se de representações midiáticas envoltas de relações de poder, uma vez que regulam condutas, modos de agir, de vestir, de se alimentar, entre outras implicações socioafetivas ${ }^{41}$.

Quando falamos do autocuidado da mulher - em suas roupas, modos, corpo e abordagens congêneres - e dos cuidados do outro - da mulher na posição de cuidar do marido, dos filhos, do lar, sendo, desse modo, compreendida como mãe, esposa e dona de casa -, não é intenção denotar que o cuidado coletivo e individual seja, em si, uma forma de opressão reiteradora de desigualdades, mas apontamos a assimetria presente nas noções de associação imediata entre mulher e responsabilidades no âmbito da família e do lar como tarefas obrigatórias para elas.

Os discursos que transparecem noções afirmadoras das mulheres como "naturalmente" adequadas ao espaço doméstico, dependentes dos homens e subordinadas ao núcleo familiar, denotam modelos limitadores e desiguais. $\mathrm{Na}$ noção de dicotomia público-privado, embora existam fronteiras borradas entre essas esferas, o espaço privado, que é cenário dessas atribuições associadas à mulher, é desvalorizado e discriminado, num movimento em que se coloca o espaço público como mais importante e reservado ao homem. A divisão do trabalho entre os sexos denota a dicotomia entre os espaços privado e público num movimento em que os homens são ligados às ocupações da esfera da vida econômica e política e às mulheres atribuem-se ocupações ligadas à domesticidade e reprodução ${ }^{42}$. Difunde-se a ideia de homem autônomo e

\footnotetext{
37 CUNHA, Maria de Fátima da. Homens e mulheres nos anos 1960/70: um modelo definido? Revista História Questões \& Debates, Curitiba, v. 34, n.0, p. 201-222, 2011.

${ }^{38}$ MATOS, Auxiliadôra Aparecida de; LOPES; Maria de Fátima. Corpo e gênero: uma análise da revista TRIP Para Mulher. Revista Estudos Feministas, Florianópolis, v. 16, n. 1, p. 61-76, 2008, p. 62.

${ }^{39}$ DEL PRIORE, Mary. Corpo a corpo com a mulher: pequena história das transformações do corpo feminino no Brasil. São Paulo: Senac, 2009, p. 73.

${ }^{40}$ BELELI, Iara Aparecida. Imagens efêmeras: gênero e sexualidade na propaganda brasileira. $29^{\circ}$ Encontro Anual da ANPOCS, 2005, Caxambu. Anais do $29^{\circ}$ Encontro Anual da ANPOCS, 2005.

${ }^{41}$ LOURO, Guacira Lopes; NECKER, Jane Felipe; GOELLNER, Silvana Vilodre. Corpo, gênero, sexualidade: um debate contemporâneo. Rio de Janeiro: Vozes, 2008.

${ }^{42}$ OKIN, op. cit., 2008.
} 
mulher dependente ${ }^{43}$, primeiro do pai, depois do marido - e, em alguns discursos, até mesmo dos filhos.

Este lugar-comum, da mulher "destinada" ao espaço doméstico, especialmente no papel de mãe além do de dona de casa, apresentado nas imagens 1, 2 e 3, de 1967, e reiterado nas imagens 4, 5 e 6, de 2014/2015, denota justamente estas noções. Os sentidos presentes nas associações que fazem essas propagandas ilustram como estereótipos e relações de gênero, mesmo através do tempo, permanecem limitadores, apresentando poucas mudanças no que se refere aos modelos femininos.

\section{Novas pautas, novos desafios: ontem e hoje}

A partir do exposto acima, podemos compreender como a saída das mulheres de casa para "trabalhar fora" é, possivelmente vista como uma atividade de mais privilégio, já que nas tarefas domésticas, além de não existir remuneração, há a ideia de que quem as faz é um servidor do outro.

Os movimentos feministas brasileiros, já nas décadas de 1960 e 1970, surgem em um contexto de contestação à ordem política instituída, manifestando descontentamento e, em alguns casos, subvertendo os códigos de conduta da época ao questionar o lugar tradicionalmente atribuído à mulher na sociedade ${ }^{44}$. É na década de 1960 que se intensificam discursos emancipatórios (de vários movimentos sociais, como o estudantil, negro, feminista, etc.) permitindo que houvessem personagens coletivos femininos que passam a ganhar notoriedade pública ${ }^{45}$.

Para as mulheres, reivindicar espaço na esfera pública não era uma negação do privado, espaço historicamente associado a elas, mas se tratava de colocar em pauta e problematizar a divisão sexual deste trabalho. Reinvindicações acerca da queda de barreiras que se apresentavam à mulher no mundo do trabalho e da política fizeram parte, inclusive, do movimento feminista dos anos 1960, embora que, ainda nesse momento, o próprio movimento feminista ressaltasse que a mulher deveria se atentar para responsabilidades específicas na família ${ }^{46}$. No bojo das reivindicações dos movimentos feministas, notava-se que a aceitação do duplo papel feminino (no mercado de trabalho e no lar) podia acirrar ainda mais as desigualdades entre homens e mulheres.

\footnotetext{
43 TÍMON, Mônica; SASTRE, Genoveva. Los sentimentos em el ámbito de la moral. Educação e pesquisa, São Paulo, v. 29, n. 2, p. 219-234, 2003.

${ }^{44}$ GIANORDOLI-NASCIMENTO, Ingrid; TRINDADE, Zeidi; SANTOS, Maria de Fátima. Mulheres brasileiras e militância política durante a Ditadura Militar: a complexa dinâmica dos processos identitários. Revista Interamericana de Psicologia, Porto Alegre, v. 41, n. 3, p. 359-370, 2007.

45 MOTTA, Alda Britto da. Mulheres velhas: elas começam a aparecer. In: PINSKY, Carla Bassanezi; PEDRO, Joana Maria (org.) Nova história das mulheres no Brasil. São Paulo: Contexto, 2012, p. 84-103.

${ }^{46}$ OKIN, op. cit., 2008.
} 
Parece correto afirmar que representações midiáticas, e na imprensa de um modo geral, essas rupturas ainda não se faziam presentes como hoje (conforme apontaremos a seguir), de modo que as representações femininas estereotipadas não apenas permaneciam, como também pareciam tomar força. Por outro lado, socialmente, a contradição da aceitação de um "duplo papel" da mulher, nos anos 1960, passa a dar espaço para o questionamento das classificações, ao passo que avaliam e revisam os papéis sociais das mulheres, como as atribuições domésticas e extra domésticas típicas de homens e mulheres, assim como papéis de mãe, esposa, dona de casa, entre outras ${ }^{47}$.

$\mathrm{Na}$ atualidade, contudo, a chamada dupla jornada da mãe que trabalha em casa e fora de casa, têm ocupado com frequência a pauta do movimento feminista, assim como a visibilidade no espaço midiático. Nos últimos anos, principalmente nas redes sociais digitais, nota-se um movimento social de uso de ferramentas como os anúncios publicitários para subverter papéis estereotipados, questionando algumas situações e condições de desigualdades.

Há, inclusive, discussões que, para além das desigualdades, colocam as assimetrias de gênero como uma forma de violência velada ou simbólica. Como é o caso da imagem 7 , que aborda diretamente a pauta da dupla jornada feminina.

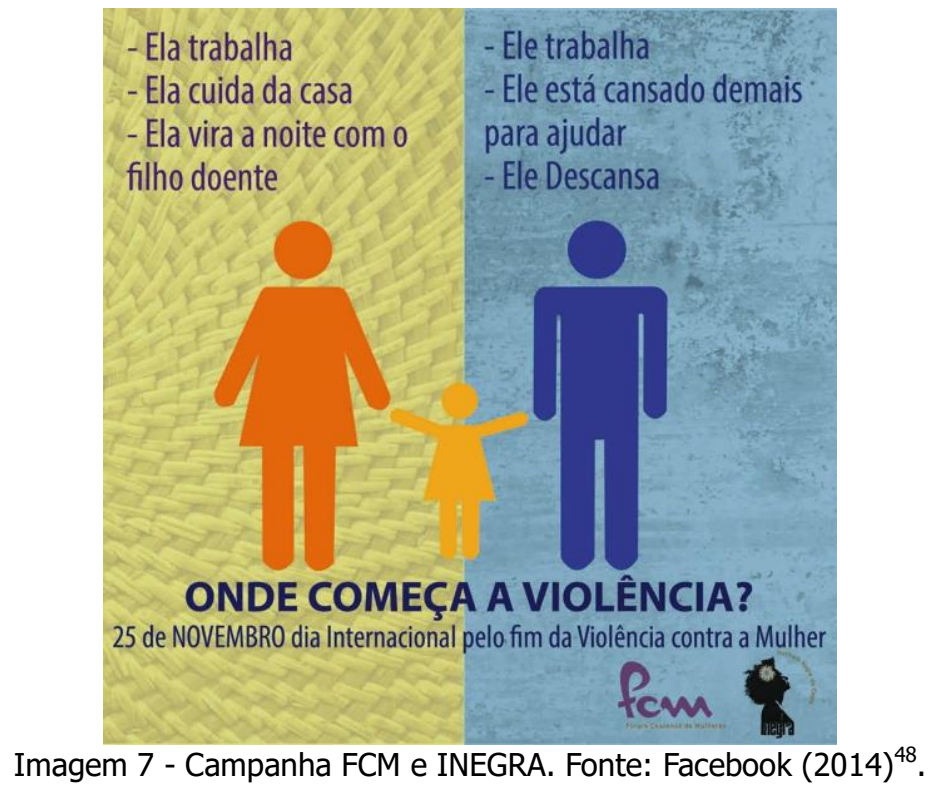

O movimento feminista, mostrando rupturas nas noções vigentes, deste modo, apropria-se da propaganda, ferramenta usualmente explorada para a construção de uma imagem subordinada da mulher, para desconstruir estereótipos e ressignificar as relações de gênero criticamente.

A imagem 7, que faz parte de uma campanha assinada pelo Fórum Cearense de Mulheres ${ }^{49}$ e Instituto Negra do Ceará ${ }^{50}$, é um exemplo de uma

\footnotetext{
${ }^{47}$ DEL PRIORE, Mary. História das mulheres no Brasil. São Paulo: Contexto, 2000.

48 Esta e outras postagens relacionadas à campanha estão disponíveis em: <http://goo.gl/oDNNhi>. Acesso em: 10 fev. 2015.
} 
dessas contraposições. Divulgada em redes sociais em novembro de 2014, as imagens colocam em debate situações cotidianas que acentuam desigualdades de gênero entre mulheres e homens valorizando uma parte em detrimento da outra.

É possível constatar que, ainda nesse anúncio, se problematiza a noção de que "homens que têm sucesso na vida pública são frequentemente desculpados por negligenciar suas famílias, enquanto as mulheres, na mesma situação, não o são"51. Essa compreensão, ainda, é também transposta na campanha assinada pelo grupo Manifesta Utilità (Imagem 8), uma organização que une designers gráficos para abordar temas relacionados aos direitos humanos.

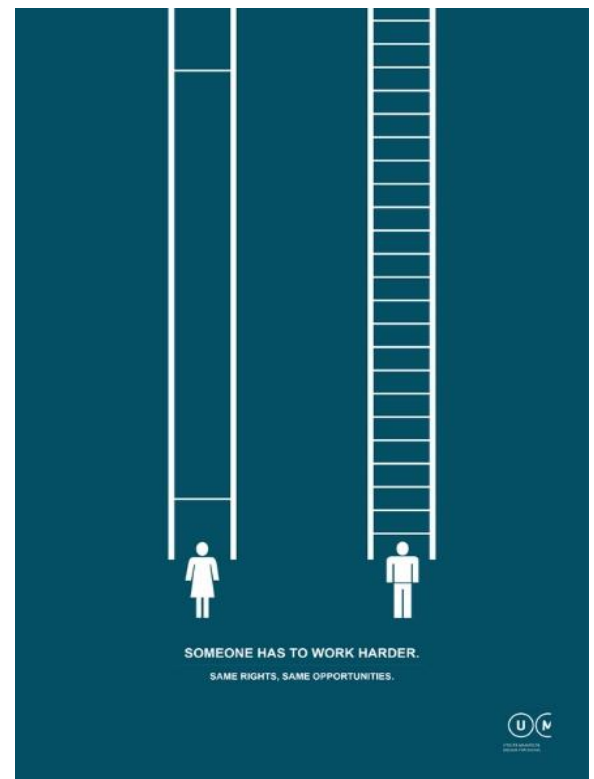

Imagem 8 - Anúncio Manifesta Utilità. Fonte: Behance $(2014)^{52}$

A imagem 8 sugere a ideia de que a mulher, em comparação ao homem, por mais que possa parecer ter oportunidades iguais, tem sua jornada de trabalho diária dificultada. A noção aqui discutida, de que há discriminações e desvalorizações que representam percalços na vivência diária feminina, se

\footnotetext{
${ }^{49}$ O Fórum Cearense de Mulheres (FCM) é uma organização feminista e antirracista, de atuação estadual composta por organizações não governamentais, mulheres vinculadas a núcleos de pesquisas de universidades, secretarias de mulheres de sindicatos e mulheres sem vínculos institucionais. Foi criado em 1994, no processo preparatório da Conferência de Beijing (Conferência de Mulheres das Nações Unidas, realizada em 1995). Site oficial: <http://www.portaldomar.org.br/sujeitos-da-mobilizacao/fcm>.

${ }^{50} \mathrm{O}$ Instituto Negra do Ceará - INEGRA é uma organização social com prioridade a mulheres negras que busca promover os valores étnicos, políticos, sociais e culturais das populações negras atuando em uma perspectiva antirracista e feminista. Site oficial: <http://inegrace.wordpress.com/author/inegrace/>.

${ }^{51}$ OKIN, op. Cit., 2008, p. 326.

${ }^{52}$ Esta peça e as demais que compõem a campanha publicitária podem ser encontradas em: $<$ https://www.behance.net/gallery/Manifesta-Utilita-human-rights/2598519>. Acesso em: 20 fev. 2015.
} 
traduz na assinatura das peças da campanha "Someone has to work harder. Same rights. Same opportunities" ${ }^{\prime 53}$, trazendo à tona as discussões de gênero ao abordar que "as instituições e práticas de gênero terão de ser muito alteradas para que as mulheres tenham oportunidades iguais às dos homens" ${ }^{\prime \prime 4}$.

Anúncios como esses, que vão na contramão de discursos sexistas e visam um enfrentamento de valores hierárquicos nas relações entre homem e mulher, são um caminho para entender os estudos de gênero. Tal perspectiva evidencia que as noções multiplicadas reiteram feminilidades e masculinidades não só a partir de características inatas (biológicas), mas também via fenômenos sociais que, mediados, por exemplo, por concepções de uma campanha de publicidade podem criar e/ou estimular modos de ser e viver ${ }^{55}$.

Discutir gênero, assim, é um processo complexo e interdisciplinar que perpassa campos como a cultura, a economia, a educação, a política e, inclusive, a linguagem. Pela linguagem, se fazem notar discursos ideológicos que retomam outros discursos, conferindo um caráter social a estes, porque há neles muitas vozes de textos que se entrecruzam no espaço e no tempo, recuperando significações, que podem ser utilizadas, inclusive, para encontrar pistas das intenções do enunciador ${ }^{56}$.

Exemplo prático disso são os marcadores sociais de diferença que dão uma "falsa neutralidade de gênero" em documentos oficiais e discussões teóricas, como uso de termos masculinos de referência, como "ele" e "homem", enraizados em nossa cultura ocidental. Historicamente, esses usos deixavam claro que a mensagem se direcionava a chefes de família masculinos, mas estas práticas, nos últimos anos, despontam para interpretações feministas que têm revelado a necessidade de uma reestruturação para evitar que, na linguagem, sejam reforçados padrões sexistas ${ }^{57}$.

Esse tipo de questionamento é pertinente justamente porque "vivemos uma longa tradição machista. $E$, de modo curioso, somos nós que a alimentamos" $^{\prime 58}$. Dentro destas problematizações, questionar os "naturalizados" papéis de gênero que claramente desvalorizam uns em função de outros faz parte da busca pela igualdade que envolve a mudança de noções engendradas num imaginário social e cultural sexista que foi se consolidando historicamente.

As questões diárias de gênero, neste sentido, precisam ser discutidas, principalmente porque é possível encontrar resistência quando se lida com uma desconstrução do que já está posto como "adequado" e "correto". Este

53 Em tradução livre: "Alguém tem que trabalhar mais. Mesmos direitos. Mesmas oportunidades".

${ }^{54}$ OKIN, op. cit., 2008, p. 327.

55 BELELI, Iara Aparecida. Corpo e identidade na propaganda. Revista Estudos Feministas, Florianópolis, v. 15, n. 1, p. 193-215, 2007.

56 BARROS, Diana Luz Pessoa de; FIORIN, José Luiz (orgs.). Dialogismo, polifonia, intertextualidade: em torno de Bakthin. São Paulo: Editora da Universidade de São Paulo, 2003.

57 Em 2014, inclusive, foi disponibilizado pelo Governo do Estado do Rio Grande do Sul o "Manual para o uso não sexista da linguagem: o que bem se diz bem se entende", disponível para consulta em: <http://goo.gl/NSjPXm>. Acesso em: 10 fev. 2015.

${ }^{58}$ DEL PRIORE, op. cit., 2014, p. 6-7. 
entendimento está, também em sintonia com as proposições do Plano Nacional de Políticas para as Mulheres (2013-2015) ${ }^{59}$, que tem como princípios orientadores a busca pela igualdade entre mulheres e homens em todos os espaços e o respeito à diversidade e combate a qualquer forma de discriminação.

Essas indicações, do mesmo modo, inclusive, alinham-se com os desafios do milênio promovidos pela Organização das Nações Unidas (ONU) ${ }^{60}$, quando, em seu terceiro objetivo, trata da importância de promover a igualdade de gênero e valorização da mulher. Dentre as sugestões de ações presentes no plano estratégico da ONU, destacam-se a divulgação dos locais dos centros de atendimento para mulheres; a realização de denúncias de casos de agressão e violência contra mulheres; o incentivo à população feminina para a busca de alternativas de geração de renda; a promoção de uma educação na qual filhos e filhas realizem, com igualdade, o trabalho cotidiano do lar; a não reprodução de expressões sexistas que atentem contra a dignidade da mulher ou a coloquem em situação de inferioridade; e o boicote à produtos que explorem o corpo feminino em sua comercialização, de modo que se exija o cumprimento da regulamentação publicitária e se fortaleça o senso crítico dos consumidores e sociedade, entre outras propostas.

\section{Considerações finais}

Vivemos em uma sociedade organizada por relações em que o modo como somos e vivemos depende de identificações de gênero. Compreender as representações, práticas e discursos que se pautam na divisão do trabalho e nas relações de poder, estereotipando a imagem feminina e fortalecendo desigualdades, permite desmistificar a associação da mulher com a esfera doméstica, com a incansável responsabilidade de cuidar de si e dos outros segundo padrões externos que vão sendo internalizados historicamente.

Neste movimento, desconstruir a consolidada estrutura social sexista gira em torno da noção de gênero como uma identidade mutável, inserida em um tempo e espaço, de origem e força cultural.

As representações femininas aqui elencadas, presentes nas imagens publicitárias da mídia impressa dos anos 1960, por exemplo, podem ter reverberado em conceitos presentes nos anúncios de hoje, conforme mostrado nas campanhas publicitárias que circularam em plataformas digitais. Questionar essas noções e perceber que modelos e padrões de gênero são historicamente reiterados, pode auxiliar na criação de políticas públicas e mudança de concepções que se minimizam as chances de que estereótipos femininos homogeneizantes ecoem ad eternum. Nesse sentido, é possível visualizar no

59 BRASIL. Plano Nacional de Políticas para as Mulheres (2013-2015). Brasília: Secretaria de Políticas para as Mulheres, 2013.

${ }^{60} \mathrm{O}$ projeto intitulado " 8 jeitos de mudar o mundo" e suas sugestões de ações está disponível em: <http://www.objetivosdomilenio.org.br/>. Acesso em: 20 fev. 2015. 
bojo de alguns movimentos e ações feministas a apropriação de instrumentos de comunicação, como a propaganda, desconstruindo representações sexistas e ressignificando as relações de gênero por um viés social e político, ao mesmo tempo em que se contrapõe às visões tradicionalmente presentes nestes meios.

As mulheres, ainda que diferentes entre si, têm sido comumente englobadas por um mesmo estereótipo que tem servido de modelo e parâmetro para dissolver diferenças. Revelando as marcações de relações entre mulheres e homens e apontando para discussões em torno deste tema, percebe-se como as estruturas sociais e as representações midiáticas ainda haverão de se modificar para promover relações de igualdade.

\section{Sobre os autores}

Frank Antonio Mezzomo é Pró-Reitor de Pesquisa e Pós-Graduação da Unespar e Coordenador do Programa de Mestrado Interdisciplinar Sociedade e Desenvolvimento, Câmpus de Campo Mourão. Líder do grupo de pesquisa Cultura e Relações de Poder e Editor da Revista NUPEM. É bolsista Produtividade da Fundação Araucária. Graduado em Filosofia e especializado em História Social na Historiografia Contemporânea pela Universidade Estadual do Oeste do Paraná (Unioeste). Mestrado e doutorado em História Cultural pela Universidade Federal de Santa Catarina (UFSC). Experiência docente na área de História, Antropologia Cultural e Filosofia. Ênfase nas pesquisas: Religião, política e cultura. E-mail: frankmezzomo@gmail.com.

Ivania Skura é mestranda e bolsista CAPES do Programa de Pós-graduação Interdisciplinar Sociedade e Desenvolvimento da Universidade Estadual do Paraná (UNESPAR), Campo Mourão - PR. Bacharela em Comunicação Social com habilitação em Publicidade e Propaganda pelo Centro Universitário Cesumar (UNICESUMAR), Maringá (PR). E-mail: ivaniaskura@hotmail.com.

Cristina Satiê de Oliveira Pátaro é docente da Universidade Estadual do Paraná, campus de Campo Mourão (Unespar) e bolsista Produtividade pela Fundação Araucária. Diretora de Pesquisa da Universidade Estadual do Paraná. Professora e vicecoordenadora do Programa de Pós-Graduação Interdisciplinar Sociedade e Desenvolvimento (Unespar, campus de Campo Mourão). Possui Doutorado em Educação pela Universidade de São Paulo (2011), mestrado em Educação pela Universidade Estadual de Campinas (2006) e graduação em Pedagogia pela Universidade Estadual de Campinas (2001). Foi Diretora de Pesquisa e Pós-Graduação do campus de Campo Mourão (2010-2013). E-mail: crispataro@gmail.com.

Artigo recebido em 28 de fevereiro de 2015. Aprovado em 10 de junho de 2015. 